\title{
Socio-instrumental Service Modelling: An Inquiry on e-Services for Tax Declarations
}

\author{
Göran Goldkuhl \\ Department of Management and Engineering, \\ Linköping University, SE-581 83 Linköping, Sweden \\ \{goran.goldkuhlaliu.se\}
}

\begin{abstract}
A socio-instrumental service modelling approach is presented through a tax declaration case study. Three different service alternatives have been investigated (two paper form alternatives and one e-service). These service alternatives have been studied through service interaction modelling, contextual service definitions and service pattern analysis. Service effects have been identified at both service parties; the service provider (the Tax Agency) and the service clients (companies). These service effects were dependent on affordances of services and service pre-conditions. These affordances can be of both social and technicalinstrumental character. This study has contributed with service modelling methods and a new socio-instrumental conceptualisation of services. Important new notions are: reciprocal service effect, interdependence of services and service preconditions, unintended service affordances, reciprocal facilitation through service interaction. These concepts lead to the new concept of co-service.
\end{abstract}

Keywords: Service, e-service, service modelling, co-service, e-government, socio-instrumental pragmatism, evaluation, practical inquiry.

\section{Introduction}

Information systems (IS) are no longer restricted to be internal organisational phenomena. They are in a growing extent used externally in interaction with stakeholders outside the organisation. Many such systems include services to other actors. We tend to consider such systems as e-services. The development of e-service applications raises new demands on information systems development (ISD). Initial steps of ISD with a focus on enterprise modelling (EM) need in such cases to involve service modelling (SM). Service modelling can thus be seen as one crucial part of a broader enterprise modelling when developing e-service applications. This means that relations to other parts of EM need to be investigated when clarifying SM. Steps have been taken in this direction concerning SM in relation to modelling of goals and value object exchange $[1,2]$ and to workflow and use-case modelling [2, 3]. Within service marketing there is a related interest into what is called service maps [4, 5]. These can be seen as a kind of service process models. These are all important contributions to $\mathrm{SM}$, but there is a need for further investigations, especially concerning modelling the interactivity of services. This follows the idea that services to large extent are co-produced by customers (clients) and suppliers (providers) [4, 6, 7, 8]. 
One great obstacle in conceptualising service modelling is that the service notion is equivocal. Reading the service marketing literature, service can mean resources, activities, processes, results, utilities, benefits, values and experiences [6, 7]. This conceptual vagueness of services spills over to the e-service notion. There seems not to be a consensual and clear definition of an e-service.

This paper addresses challenges of service modelling. Besides issues of method and model uses, this includes foundational conceptual matters of (e-)services and eservice relations to business processes. The paper develops a distinct perspective on service modelling: A socio-instrumental approach to service modelling. This approach has evolved in a multi-grounded fashion through a diagnostic case study. Multi-grounded means that it has been theory-informed as well as emerging through practical use in a real-life modelling situation [26]. This is more fully described in section 2 below. The chosen case study deals with tax declarations; an e-government service. This means that the paper contributes with knowledge concerning egov services (public e-services). The paper can be said to have multiple purposes and contributions. It contributes with

- A socio-instrumental conceptualisation of services, e-services and egov services

- A service modelling approach

- An egov case study

Most important of the paper is the service conceptualisation and the over-all service modelling approach. Specific notations are presented, but the main focus is not on different notational elements. It is beyond the scope to make any comparison with other EM notations.

\section{Research Approach}

The research approach can be characterised as a practical inquiry [9] following the spirits of pragmatism and its notion of pragmatic inquiry $[10,11]$. As such, this practical inquiry comprises action research, design research and evaluation research. These three aspects will be further described below. Practical inquiry means a study in one or several local practices with a dual purpose of contributing both to these local practices and to general knowledge. In this respect it coincides with purposes of action research [12]. One difference is that general knowledge of practical inquiry is aimed both for general practices and for the scientific community. The demands on action research are not defined [12] as contributing to general practice outside changed local practices.

The author of this paper has participated in an inquiry at the Swedish Tax Agency (STA). An e-service for companies' tax declarations was launched some years ago. It has not been a success since there are only $30 \%$ of the companies that use this eservice. The rest of the companies use the traditional way with a paper form for tax declarations. STA has a clear ambition to increase the amount of e-declarations. A joint project was started by STA and some researchers in order to investigate causes for this missing success and to redesign the e-service to be more attractive in order to increase its usage. 
The research reported in this paper is delimited to the initial diagnosis phase. This means that it is based on an evaluative endeavour. The evaluation consisted of modelling of the e-service as well as the paper form service. There was a clear diagnostic purpose to better understand why the companies did not use the e-service. STA had earlier conducted a broad survey among companies concerning tax declarations. This diagnostic study was based on the earlier survey and the purpose was to disclose yet hidden patterns of use and non-use in order to build an informed basis for subsequent redesign. The conducted evaluation contributed to this local practice (STA) with new knowledge as a kind of evaluation research [13]. The evaluation has been used as an exploratory empirical study in the research process. It is exploratory in the sense that the evaluation was used to try out and continually refine the socio-pragmatic service modelling approach described in this paper. This means that the evaluation (both process and product) form the empirical basis for abstraction and theorizing.

The collaboration between Swedish Tax Agency and the researchers can be characterized as action research (AR). It aims at local practice changes besides contribution to scientific knowledge. This part of the research cannot be said to constitute a full action research cycle according to [12]. It is limited to a diagnosis intervention [9]. For a full AR cycle it requires also action planning (=design intervention) and action taking (=implementation) [12,9]. An evaluation/diagnosis intervention, as conducted in this case, is thus a partial action research [9].

A great part of the evaluation of the services at STA has consisted of service modelling. This means creation of model-artefacts based on languages/notations. Integrated with this modelling there has been an evolution and adaptation of concepts and notations. The creation of model-artefacts and model-languages can be interpreted as a kind of design research (DR). Results of design research are defined as constructs, methods and models $[15,16]$. This practical inquiry has led to new knowledge concerning service conceptualisations (i.e. constructs in DR), new and adapted methods/modelling languages (i.e. methods in DR) and the creation of situational models of declaration services (models in DR). The models are parts of evaluative statements concerning the declaration services. The models as such have been continuously (meta-)evaluated concerning their practical usefulness and conceptual cohesion. The evolving socio-pragmatic perspective on services can be seen as an embryonic design theory $[17,18,26]$.

\section{Some Fundamentals of Socio-instrumental Pragmatism}

The basic perspective used for developing this service modelling approach has been socio-instrumental pragmatism (SIP) $[9,19,20]$. This is an eclectic approach adapted for IS studies. SIP is an integration and synthesis of several action-oriented theories from reference disciplines to IS. SIP has been inspired by speech act theory, pragmatic philosophy, symbolic interactionism, social action theories, affordance theory and activity theory among others. Confer [19, 20] for more details on theoretical background. One key idea behind SIP is that this framework should be possible to use for many different research areas in IS aiming for seamless theorizing [19]. This means that it should be possible to use for conceptualization of (e-)services among other areas. 
The basic concepts of SIP are actor/agent, action and object. Other important concepts are action disposition (by actors/agents) and relation (between actors). SIP concepts are visualized in figure 1. This figure describes socio-instrumental action; one actor (the focused actor) conducts an intervention (interventive action) leading to a result object intended for another actor (the addressee). The addressee receives this object which is another type of action. Actions respective objects can be material or communicative. The focused actor can deliver a material object to the addressee or he can express (say or write) something directed to the addressee. Both material and communicative actions give rise to (changed) social relations between the actors [19].

There are different kinds of objects that have different functions in the actions. In order to produce a result object, the actor may use some base object and some instrument object. A base object is something that is transformed (to a result object) through the interventive action. Instruments are utilized in interventive actions in order to enable and/or facilitate the creation of result objects.

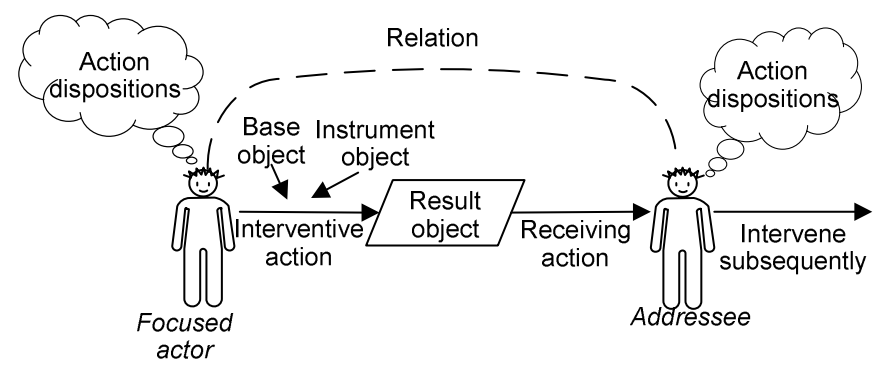

Fig. 1. Socio-instrumental action (based on [19])

SIP acknowledges both the social and instrumental character of interaction between actors. There are communicative objects that inform addressees and regulate the relations between the actors. There may also be technical/material objects which need to be handled by the actors. Materiality constrains and facilitates actions [21, 19]. Actions are performed by human actors; but some actions may be performed by technical artefacts (agents) like IT-systems. Such actions need to be well-defined and they should always be performed on behalf of some human actor.

Another important notion in socio-instrumental pragmatism is affordance. This notion emanates from affordance theory [22]; which is an ecological theory of perception. According to this theory, humans (as well as other species) perceive the surrounding world in terms of what action possibilities it affords to us. An affordance is an action possibility for the actor provided/offered to him. It is something that humans can do with, through and in relation to the environment. Instruments and bases are affordances for the actor to act and create a result object. The original affordance concept was mainly focused on material conditions. But there are also sociocommunicative affordances which through symbols influence the actor and give rise to action possibilities. Affordances are not only positive. One can also talk about negative affordances, i.e. elements that obstruct or inhibit action. There may be material affordances that are positive (enable or facilitate action) or negative (obstruct or inhibit action). There may also be communicative affordances that are positive 
(e.g. guidance, advices) or negative (as constraining regulations). Information that is misleading or confusing can also be seen as negative affordances.

\section{Socio-instrumental Service Modelling: A Taxation Case Study}

This section describes of parts the case study at the Swedish Tax Agency introduced in section 2 above. It describes three types of models:

- Service interaction models

- Contextual service definitions

- Service pattern models

The modelling has been driven by the author/researcher in continual interaction with a STA officer who is responsible for development of the e-declaration service. Empirical bases for the service modelling has, besides dialogues with STA staff, been results from an earlier survey among companies concerning use and non-use of the e-service, taxation regulations, other STA documents and the e-declaration service. The different service models have been continually inspected and validated by the STA officer.

\subsection{Service Interaction Modelling}

Service is often described as a co-production between a service provider and a client $[6,7,8]$. Even if this concept of co-production may be questionable, it is obvious that there is often an interaction going on between the provider and the client. This makes it important to describe this interaction in order to clarify the service's role for the client as well as for the provider $[4,5]$. I would hypothesize that it is often more important to make service interaction models rather than business process models (workflow models) in service analysis and design [9]. Anyhow, in this study both service interaction models and business process models have been created. The process models are not presented or analysed in this paper since they have not influenced the socio-instrumental analysis to any significant degree.

Service interaction modelling consists of describing the basic interaction structure between the service provider and the service client concerning provision and use of the services. The main interest in the inquiry was towards the e-service (eTax Declaration). It was however important to compare it with the alternative service, declaration via a traditional paper form. This comparison was needed in order to better understand why so many companies still chose to use the paper form declaration.

Service interaction modelling started with a describing tax declaration in a generic way independent of how to make and submit the tax declaration. Based on this generic service interaction model, different services cases were identified. There were two main types of service cases (e-service vs. paper form). But there existed also some sub-cases of these two services cases. In this paper I will describe three service variants $^{1}$; two paper form variants and one generalized e-service type. The division

${ }^{1}$ The notion of service variant is inspired by the notion of business process variant [23]. It has been found important in process modeling to distinguish between different process variants in order to make a clarifying analysis. 
into different service variants was important since it makes a comparison possible and this can lead to conclusions concerning advantages and disadvantages. It is a way of identifying "analysis units". Each such unit (i.e. service variant) will be possible to describe in sufficient detail.

In figure 2 a service interaction model (called "InterActor Diagram") is presented for the ordinary paper form variant. It describes the two main interactors; the Swedish Tax Agency (service provider) and the company (as service client). It depicts also the government as an actor, since it produces tax regulations that govern the tax declaration process. Service interaction modelling relies on an exchange perspective rooted in SIP [23,9] and the language action perspective [29]. What are the exchanges made in processes of agreement and accomplishment? What exchange actions are performed and thus what objects are exchanged? The regulative character of tax declaration makes this case rather distinctive.

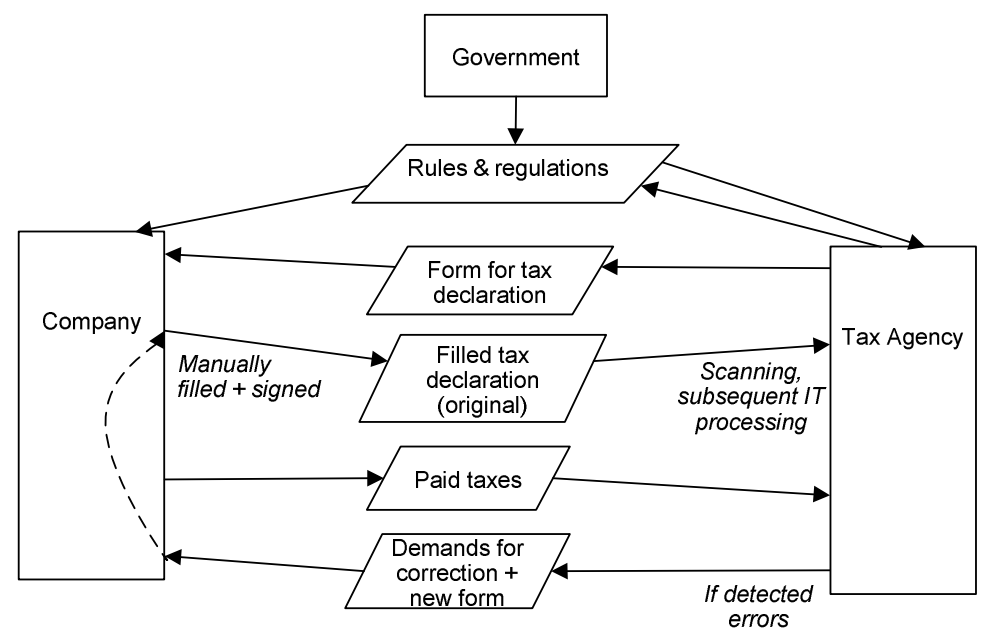

Fig. 2. Paper form declaration (use of original form) - InterActor Diagram

STA delivers paper declaration forms every month to companies. The company fills out the tax declaration form and submits it to the Tax Agency. The paper form is scanned and later IT processed where errors might be detected which might lead to demands for corrections.

The e-service variant is described in figure 3. In this case there is no paper form. The company fills out an e-form within the e-service. The declaration will be signed through an electronic Id. The authorized signatory needs to make request for an eId permit before the e-service is used the first time. The Tax Agency will receive the declaration electronically which will facilitate further IT processing. The e-service application will conduct number checks which will lead to fewer errors in received tax declarations. 


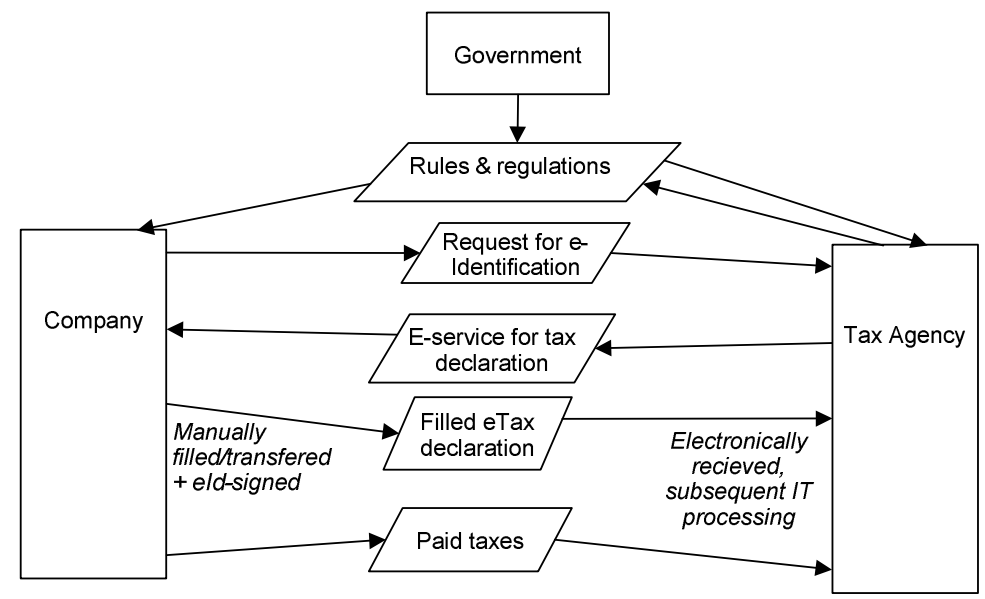

Fig. 3. eTax declaration - InterActor Diagram

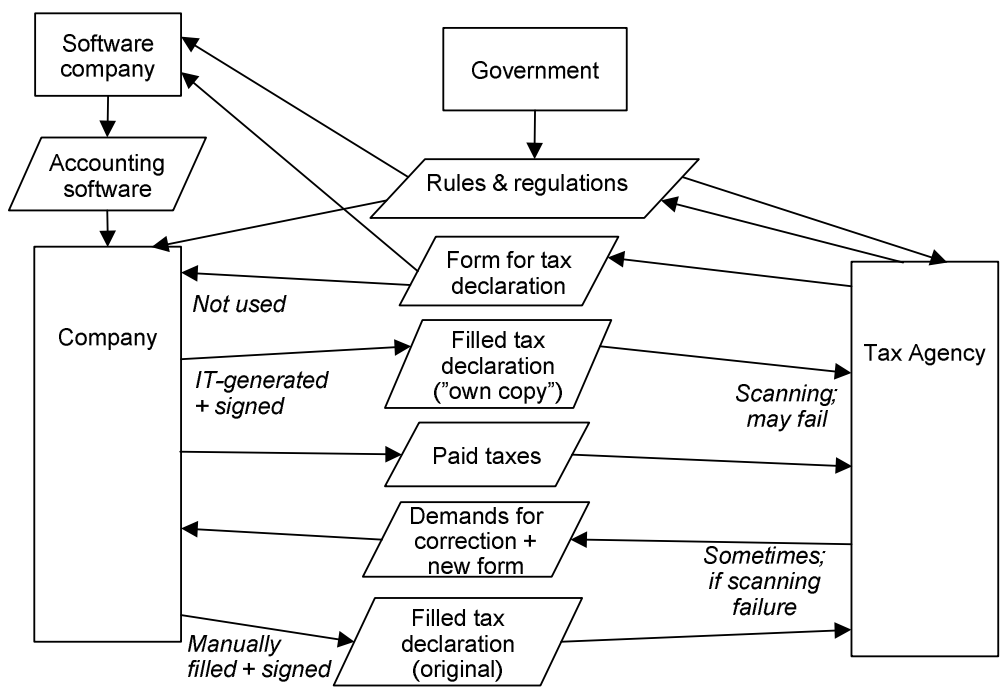

Fig. 4. Paper form declaration (use of "own copy") - InterActor Diagram

There are companies which use the paper form variant together with their accounting software. The acquired software has capabilities to print out a tax declaration form with filled numbers. There is however one problem with this service case alternative. The Tax Agency's scanning equipment is so sensitive that it cannot (always) process forms that are printed from the companies' software systems. STA personnel might need to manually register the declaration or sometimes it can be resent to the company with demands for a new declaration to be filled out. 


\subsection{Contextual Service Definition}

An e-service should be a service. Why else should we call it an e-service? As stated in section 1 above, there are however not so clear conceptions of what a service is. Service can for example designate activity, use, experience and effect $[6,7]$. In order to analyse and compare services it is pivotal to have a clear service conception. I agree that it is important to understand different service aspects like service actions, service use and service effects. But it is necessary to have a clear conception of what a service is for service evaluation and redesign. It is not acceptable to have equivocal meanings. For a more detailed critique of this vagueness in the service notion cf. [27].

For most services - what is done is the most important. Clients do not only request actions. They request something to be done. Clients request that actions will be accomplished leading to results that are useful for the client. This means that it is not the doing; instead what is done that is the essential of a service [27]. 'Service' is not just a noun-making of the verb 'serve'. Service is what is provided to the client through serving. I call the service to the client a service fact. This means what is done and thus possible for the client to experience or use. This means that a service comprises also affordances following the reasoning above in section 3 . Through the use of a service the client may be able to perform actions otherwise not doable. A service has affordances for further action.

Table 1. Contextual service definition for two tax declaration services

\begin{tabular}{|c|c|c|}
\hline $\begin{array}{l}\text { Service type } \\
\text { Service category }\end{array}$ & Paper form service & Electronic service \\
\hline Service provider & Swedish Tax Agency & Swedish Tax Agency \\
\hline Service pre-conditions & Tax regulations & Tax regulations, Internet \\
\hline Service provision actions & Deliver paper form & $\begin{array}{l}\text { Establish e-service } \\
\text { application } \\
\text { (eTax Declaration) }\end{array}$ \\
\hline Service techno-agent & -- & $\begin{array}{l}\text { eTax Declaration } \\
\text { (e-service application) }\end{array}$ \\
\hline $\begin{array}{l}\text { Service to client } \\
\text { (Service fact) }\end{array}$ & Delivered paper form & E-service \\
\hline Service client & Company & Company \\
\hline Service use \& effects & $\begin{array}{l}\text { Company can fill out, sign } \\
\text { and submit declaration by } \\
\text { mail }\end{array}$ & $\begin{array}{l}\text { Company can fill out and } \\
\text { get declaration checked, } \\
\text { sign and submit it } \\
\text { electronically }\end{array}$ \\
\hline
\end{tabular}

In table 1 contextual service definitions are given for the two declaration services. Contextual means that not only the service itself is defined. Several other (contextual) aspects are also described, as the service provider, service pre-conditions, service provision actions conducted by the provider, the client and the service use and possible effects. The contextual service definition also includes "service techno-agent" which means a technical performer of actions (like an e-service application or some other type of IT artefact). Having two services in one table makes them easier to compare. 


\subsection{Service Pattern Analysis}

Services should be valuable to clients $[7,8]$. The use of a service should give rise to effects that are conceived as valuable to the client. The service provider should deliver a service that is valuable to the client. This is essential following the general service discourse. There is a provider that should direct a valuable service to the client. Even if there, in service theory, is acknowledged that the client take part in the production of value [8], the whole focus is on value to the client. Total emphasis is on how the client should be satisfied through the service. There is no or little attention to how the service provision affects the provider in positive or negative terms.

When studying this service case (tax declaration) it is obvious that the different service designs will render different effects to both STA as service provider and the company as service client. It is not sufficient to analyse only service effects at the company. Different effects have arisen at both parties. The inquiry perspective has been on reciprocal service effects. This means service effects at both parties.

Service effects might not only be positive. In this case it was important to study positive and negative effects at both parties. It was however not sufficient to just identify these different effects. To evaluate the services it was necessary to make a causal analysis why these different effects were rendered. To make this causal analysis of reciprocal service effects, the socio-instrumental framework (introduced in section 3 above) was used. Services are considered as affordances. They offer action possibilities to a service user. Service affordances can be both positive and negative. A positive affordance will enable and/or facilitate actions. A negative affordance will obstruct or inhibit actions. The focus in the causal search was not only on the service itself. Different accompanying service pre-conditions were analysed, like regulations, accounting software and scanning equipment. This means an interest on both social matters (e.g. regulations) and technical-instrumental matters (e.g. scanning equipment) and how these different pre-conditions influenced the different parties in their actions. This follows the essence of socio-instrumental pragmatism.

This cause and effect analysis of services was labelled a socio-pragmatic service pattern analysis. The three services cases were investigated concerning reciprocal service effects and their socio-instrumental causes. Each service case was described in a service pattern diagram (figure 5-7).

A service pattern diagram is thus a kind of cause-effect diagram (see table 2). It describes socio-pragmatic patterns, which means that actions, different pre-conditions for actions and results and effects of actions are described. Action pre-conditions can be both internal (e.g. intentions, dispositions) and external objects (of both communicative and material character). The main type of relation is "lead-to", i.e. a cause-andeffect relation. The socio-pragmatic character means that it is not always a strict deterministic relation. Deliberation, intentionality and social interactivity are at stake. The diagrams do not only describe causal relations. They can also describe relations of inhibition character. The diagrams are divided in two parts; each part for each actor in order to clarify conditions, actions and effects clearly related to each actor. This makes also the interactivity character of the services to come through. Service pattern diagrams are re-developments of cause-effect problem diagrams [28]. 


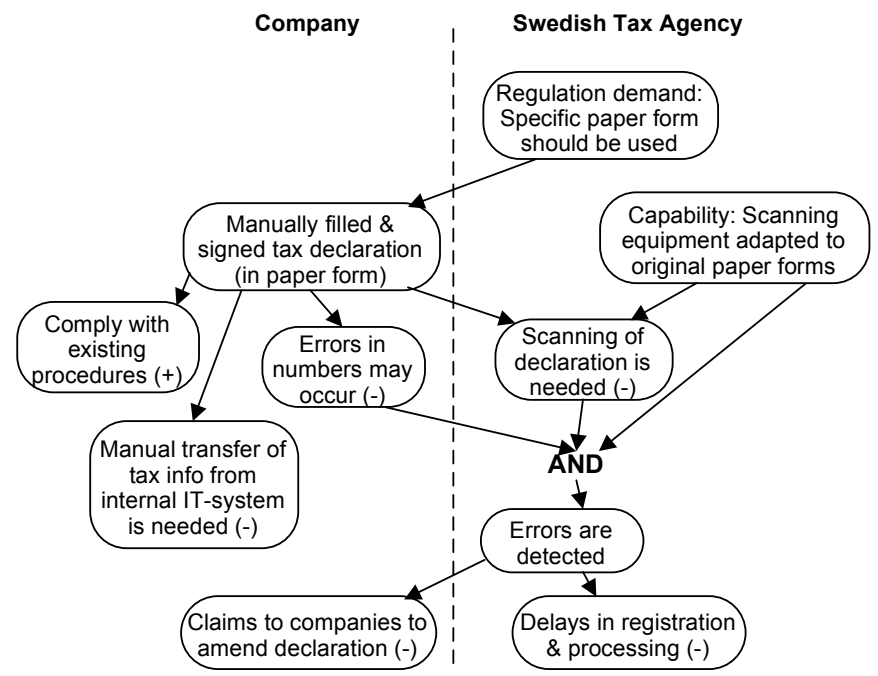

Fig. 5. Paper form declaration (use of original form) - Service pattern diagram

Table 2. Legend Service pattern diagrams

\begin{tabular}{|l|l|l|}
\hline & $\longrightarrow$ & \\
\hline $\begin{array}{l}\text { Action, action pre-condition, } \\
\text { action effect }\end{array}$ & "Lead-to" relation & "Inhibit" relation \\
\hline
\end{tabular}

Figure 5 describes the paper form service case; where the company uses the original paper form. As can be seen from this diagram there are negative effects for the Tax Agency, like the need to scan the declaration and thus delays in processing. Why do companies still use this service option? This was a key question in the service inquiry. One answer can be found from the diagram: Habit! The companies are accustomed to this kind of procedure. They tend to follow their routines if they do not see that they can gain a lot from shifting to new services.

More answers can be found from diagram 6 which describes the case where the company uses their accounting software system to generate a tax declaration in paper form ("own copy" alternative). This alternative will give certain advantages to the companies. They do not have to fill out the forms manually. Numbers are checked by the software. This alternative may however have negative consequences for STA. As said above (section 4.1), the STA scanning equipment is so sensitive that it sometimes cannot process forms that are printed from the companies' software systems.

This alternative is dependent on the capabilities of existing software. The accounting systems need to have capabilities (i.e. certain affordances) to print forms according to the standards of the Tax Agency. The software companies have used the STA paper forms to adapt their software (figure 4 above). According to regulations, this alternative is not acceptable. There is a regulation that states that original form should 
be used. However many companies do not comply with this regulation since their internal efficiency demands give preference to the use of the accounting software for printing the form. This case can be said to be an unintentional service case. It is unintentional from the perspective of the Tax Agency. On the other hand companies use this option intentionally to deliver tax declarations more easily.

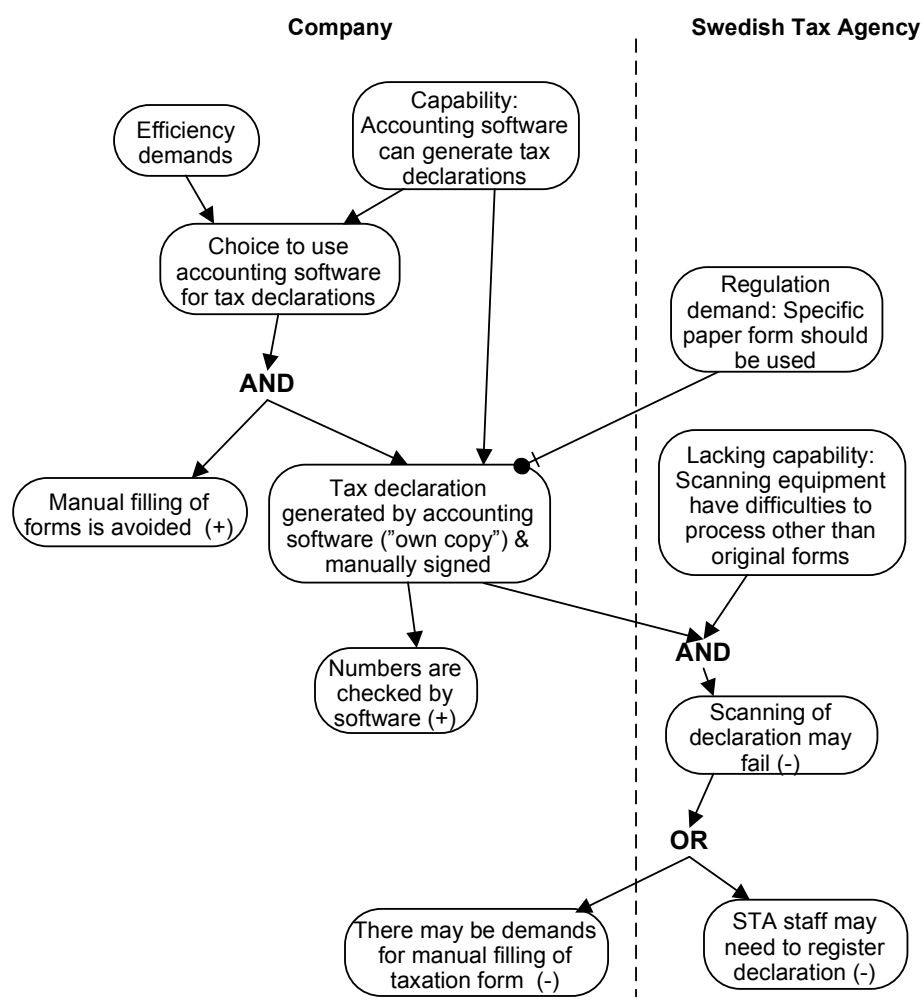

Fig. 6. Paper form declaration (use of "own copy”) - Service pattern diagram

Even more answers can be found from the e-service diagram (figure 7). For the companies there might be seen easier to generate a tax declaration from their own software than manually fill out the e-form of the e-service. They need also to acquire an e-Identification to use the e-service. The companies do not have much to win to use the e-service alternative instead of using their own software for generation of tax declarations. The gains of the e-service alternative are to be found at the Tax Agency. They will get the tax declaration in electronic form which will enable a smooth continual processing. Scanning of tax declarations is avoided in this case. The e-service application will check numbers which will lead to fewer errors in declarations. 


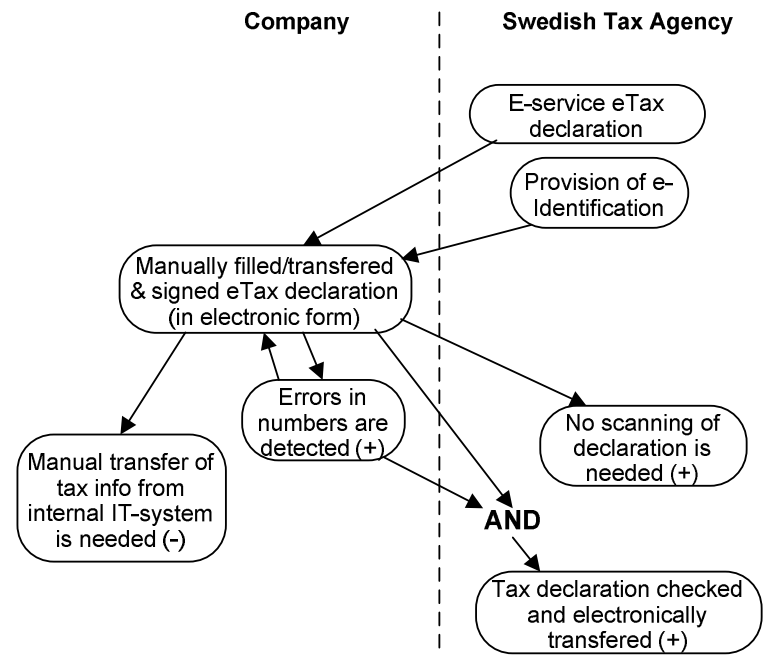

Fig. 7. eTax declaration (e-service) - Service pattern diagram

\section{A Socio-instrumental Understanding of Services and Co-services}

The socio-instrumental service modelling of tax declaration services described above gave rise to several positive inquiry effects. New circumstances were discovered and revealed concerning use and non-use of the e-service. The different models gave a clarifying picture of why so many companies still do not use the e-service. This was acknowledged through interaction with Tax Agency personnel. The models have also been used as a basis for further inquiries concerning these services.

What conclusions of general character can be drawn from this case study? The study has developed and adopted a socio-instrumental approach to service modelling and inquiry. This approach has been applicable and useful in this egov service case. I would like to claim that the conclusions, clarified below, should be valid for governmental services in general. Concepts have been abstracted in order to be applicable for such service analysis. Some of these concepts, perhaps all, might also be applicable and useful in other service settings. This needs however to be shown through further empirical inquires.

The purpose of this paper is not to compare the socio-instrumental approach and its modelling languages with other EM methods. A few comments will just be interposed. The notations used here (figures 2-7; table 1) are simple and flexible. Sophisticated notational distinctions as e.g. in $\mathrm{i}^{*}[1,30]$ and $\mathrm{e}^{3}$ value $[1]$ have been avoided. The underlying perspective (socio-instrumental pragmatism with emphasis on service interactions and service patterns) gives rich expressiveness in models. The basic conceptualisations are used together the notations in a rather free way.

This study has contributed with several important notions. One key notion is reciprocal service effect. This means that effects of service use can arise for both parties in the service interaction; i.e. both service provider and service client. These effects can 
be of both positive and negative character. The different service alternatives and their uses gave rise to different effects for the two parties. Some effects were positive and some effects were negative.

Another key notion in this socio-instrumental service conceptualisation is the interdependence of services and service pre-conditions. In order to understand service effects it is necessary to study services as well as service pre-conditions of social and instrumental character at each party. To understand why certain service effects arise (e.g. scanning failure) it was necessary to investigate service pre-conditions at each party (e.g. capabilities of accounting software and scanning equipment). It was not only necessary to understand the capabilities and deficiencies of technical instruments (as mentioned above) but also demands and deliberations of social characters (e.g. tax regulations and companies' efficiency demands).

Another important notion in this emerging service conceptualisation is unintended service affordances. Services may have unintended affordances which can be used to give rise to negative affordances and effects. The Tax Agency's paper form led to unintended positive affordances for the companies. The distributed paper form enabled software companies to develop accounting software with capabilities to print tax declarations. And this enabled companies to use such software to print tax declarations directly from their accounting systems and thus avoiding manual filling out of forms. Such software-generated declaration forms had the unintended negative affordances for the Tax Agency of not being able to scan them through the scanning equipment.

Following these different conceptualisations another important notion appears: $R e$ ciprocal facilitation through service interaction. This means that the two parties facilitate for each other. It is not only a one-sided service delivery from the service provider to the service client. What the client does and how this is performed will also have effects for the provider. The service is not only for the client. The service is both for client and provider. A new concept emerges from this discussion: Co-service.

A co-service is something arranged that should have positive affordances and positive effects for both parties in a service interaction. The co-service perspective emphasises reciprocal facilitation.

This means that it should not be confused with the "co-production of service value" perspective [8]. That perspective involves the customer/client in the service/value production. The service seems however still to be seen as something aimed for and restricted to the client. The co-service perspective emphasises that value for both parties are important and should be acknowledged. The socio-instrumental co-service perspective also acknowledges that co-service interaction (and its design) are processes of "take and give". There are trade-offs and pay-offs between the two parties. Coservice interaction may sometimes comprise reciprocal inhibition. Co-services mean that valuable and non-valuable effects are created by and for both parties.

Is co-service is a special kind of service or is it a special perspective on all kinds of services? It is yet too early to answer this question unequivocally. It is definitely a perspective on services that emphasise the dual roles of some services. I would not yet dare to claim that is a perspective applicable for all types of services. Some services (like governmental e-services) would be easier to consider as co-services than others. Many governmental e-services have a two-way communication character $[9,24,25]$, i.e. the client (citizen) and the provider (governmental agency) are both communicators and 
information recipients. The two parties should facilitate for each other. Public e-services should be seen as co-services.

\section{Conclusions}

This paper has presented a socio-instrumental approach to service modelling. This approach has emerged through an inquiry on tax declaration services which was presented in section 4 above. The approach to service modelling consists of conceptualisations and modelling methods. The modelling process consisted of three steps: 1) service interaction modelling, 2) contextual service definition and 3) service pattern analysis. Service interaction modelling follows the principle of provider-client interactivity and participation of the client in the service process $[4,6,7,8]$. Contextual service definition tries to capture several different aspects of services $[6,7,27]$. Service pattern analysis investigates services and service pre-conditions as socioinstrumental affordances $[22,19,20]$ and identifies positive and negative effects at both parties through uses of these service affordances.

Through the empirical inquiry and the evolution of modelling methods a socioinstrumental conceptualisation of services have emerged. Several important notions have been put forth (section 5 above) for example the notion of co-services. This means that valuable and non-valuable effects are created for both service parties through service interaction. Further research will demonstrate the domain of applicability of this service conceptualisation. It has here been used in a governmental service setting. Whether different proposed concepts are applicable beyond this context will be shown through future studies. One important contribution of this study is that it once more (cf. [9, 27] for other examples) has shown the applicability and usefulness of socio-instrumental pragmatism as a generative theory for creating new relevant models and methods within IS as well as concrete situational results of value.

Acknowledgments. This research has been financially supported by the Swedish Governmental Agency for Innovation Systems (VINNOVA).

\section{References}

1. Gordijn, J., Yu, E., van der Raadt, B.: E-service design using i* and e3value modelling. IEEE Software, 26-33 (May/June 2006)

2. Henkel, M., Perjons, E., Zdravkovic, J.: A value-based foundation for service modelling. In: The European Conference on Web Services (ECOWS 2006), Zurich (2006)

3. Anzböck, R., Dustdar, S.: Modeling Medical E-services. In: Desel, J., Pernici, B., Weske, M. (eds.) BPM 2004. LNCS, vol. 3080, pp. 49-65. Springer, Heidelberg (2004)

4. Kingman-Brundage, J.: Service mapping: Back to basics. In: Glynn, W.J., Barnes, J.G. (eds.) Understanding service management. John Wiley, Chichester (1995)

5. Getz, D., O’Neill, M., Carlsen, J.: Service quality evaluation at events through service mapping. Journal of Travel Research 39, 380-390 (2001)

6. Grönroos, C.: Service marketing and management. Managing the moments of truths in service marketing. Lexington Books, Lexington (1990)

7. Edvardsson, B., Gustafsson, A., Johnson, M.D., Sandén, B.: New service development and innovation in the new economy. Studentlitteratur, Lund (2000) 
8. Ramirez, R.: Value co-production: intellectual origins and implications for practice and research. Strategic Management Journal 20, 49-65 (1999)

9. Goldkuhl, G.: What does it mean to serve the citizen in e-services? - Towards a practical theory founded in socio-instrumental pragmatism. International Journal of Public Information Systems 2007(3), 135-159 (2007)

10. Dewey, J.: Logic: The theory of inquiry. Henry Holt, New York (1938)

11. Cronen, V.: Practical theory, practical art, and the pragmatic-systemic account of inquiry. Communication Theory 11(1), 14-35 (2001)

12. Susman, G.I., Evered, R.D.: An assessment of the scientific merits of action research. Administrative Science Quarterly 23(4), 582-603 (1978)

13. Van der Knaap, P.: Theory-based evaluation and learning: Possibilities and challenges. Evaluation 10(1), 16-34 (2004)

14. March, S.T., Smith, G.F.: Design and natural science research in information technology. Decision Support Systems 15(4), 251-266 (1995)

15. Hevner, A.R., March, S.T., Park, J., Ram, S.: Design science in information systems research. MIS Quarterly 28(1), 75-105 (2004)

16. Walls, J.G., Widmeyer, G.R., El Sawy, O.A.: Building an information systems design theory for vigilant EIS. Information Systems Research 3(1), 36-59 (1992)

17. Gregor, S., Jones, D.: The anatomy of a design theory. JAIS 8(5), 312-335 (2007)

18. Goldkuhl, G.: Socio-Instrumental Pragmatism: A theoretical synthesis for pragmatic conceptualisation in information systems. In: Proceedings of the 3rd Intl. Conf. on Action in Language, Organisations and Information Systems, University of Limerick (2005)

19. Goldkuhl, G., Ågerfalk, P.J.: IT Artefacts as Socio-Pragmatic Instruments: Reconciling the Pragmatic, Social, Semiotic and Technical. International Journal of Technology and Human Interaction 1(3), 29-43 (2005)

20. Wertsch, J.V.: Mind as action. Oxford University Press, New York (1998)

21. Gibson, J.J.: The ecological approach to visual perception. Houghton Mifflin, Boston (1979)

22. Lind, M., Goldkuhl, G.: Designing business process variants - using the BAT framework as a pragmatic lens. In: Bussler, C.J., Haller, A. (eds.) BPM 2005. LNCS, vol. 3812, pp. 408-420. Springer, Heidelberg (2006)

23. Ancarini, A.: Towards quality e-service in the public sector: The evolution of web sites in the local public service sector. Managing Service Quality 15(1), 6-23 (2005)

24. Wimmer, M.A.: Integrated Service Modelling for Online One-stop Government. Electronic Markets 12(3), 149-156 (2002)

25. Goldkuhl, G.: Design theories in information systems - a need for multi-grounding. Journal of Information Technology Theory and Application (JITTA) 6(2), 59-72 (2004)

26. Goldkuhl, G., Röstlinger, A.: Beyond goods and services - an elaborate product classification on pragmatic grounds. In: Proc. of Quality in Services (QUIS 7), Karlstad (2000)

27. Goldkuhl, G., Röstlinger, A.: Joint elicitation of problems: An important aspect of change analysis. In: Avison, D., et al. (eds.) Human, organizational and social dimensions of Information systems development. North-Holland, Amsterdam (1993)

28. Winograd, T., Flores, F.: Understanding computers and cognition: A new foundation for design. Ablex, Norwood (1986)

29. Yu, E.: Towards Modelling and Reasoning Support for Early-Phase Requirements Engineering. In: Proc. 3rd IEEE Int'l Symp. Requirements Eng. (RE 1997), pp. 226-235. IEEE CS Press, Los Alamitos (1997) 